\title{
FOODBORNE ZOONOTIC AGENTS AND THEIR FOOD BIOTERRORISM POTENTIAL: A REVIEW
}

\author{
Y. D. TUMBARSKI \\ Department of Microbiology, University of Food Technologies, \\ Plovdiv, Bulgaria
}

\begin{abstract}
Summary
Tumbarski, Y. D., 2020. Foodborne zoonotic agents and their food bioterrorism potential: A review. Bulg. J. Vet. Med., 23, No 2, 147-159.

Bioterrorism is an act of deliberate release and dissemination of biological agents such as pathogenic microorganisms or their products in a naturally occurring or human-modified form. Bioterrorist attacks are aimed at causing death, disease or other biological malfunction in humans, animals or plants, in order to achieve certain political goals through creating fear and panic among the population and influencing government's behaviour. Historical data showed that zoonotic pathogens have been most commonly used as agents for bioterrorism. Applied through the food production systems or directly to processed foods as biological weapons, zoonotic pathogens can have fast and devastating effects on human health with enormous economic and social impact. Despite the development of different countermeasures and the application of hazard analysis and critical control point (HACCP) systems in the food industry, the bioterrorists' attacks as intentional acts cannot be predicted, but could be avoided by strengthening food control measures.
\end{abstract}

Key words: bioweapons, food bioterrorism, foodborne pathogens, HACCP systems, terrorism, zoonoses

\section{INTRODUCTION}

The aim of terrorism is not only to kill and destroy, but to create fear, panic and insecurity. Contemporary terrorist threats are targeted to the entire system of international relations and can affect each country directly or indirectly, since the economic prosperity strongly depends on stability and security (Tumbarska, 2018). In this respect, biological weapons could be an attractive alternative of conventional weapons and a suitable tool for achieving terrorist goals.
Bioterrorism is defined as intentional release and dissemination of biological agents. The group of biological agents includes pathogenic microorganisms (viruses, bacteria and fungi) or their products (toxins), which could be in a naturally occurring or human-modified form (Solodoukhina, 2011). In both cases, they are used to cause death, disease or other biological malfunction in humans, animals, plants or other living organisms, in order to influence the government's behaviour 
or to intimidate the population. Biological weapons are relatively easy and inexpensive to produce, cause death or disabling diseases, and can be spread in large geographic areas (Ryan, 2008).

Biological weapons are complex systems that disseminate pathogenic microorganisms or their toxins to harm or kill humans, animals or plants. They generally consist of two parts - a biological agent and a delivery system. The biological agents could be modified in order to increase their virulence, antibiotic and vaccine resistance, or to improve their ability to be spread into the environment through the air, water, food or person-to-person contact. Different delivery systems as missiles, bombs, grenades, rockets as well as spray-tanks mounted on aircraft, vehicles and boats have been created under the programmes for bioweapons development. According to the United Nations (UN) efforts to develop delivery devices for assassinations or sabotage operations, including a variety of sprays, brushes and injection systems as well as means for contaminating food and clothing have also been documented (Anonymous, 1972).

Contaminating food is a popular method of terrorising civilian populations during wartime or due to different motivations - economic (targeted to financially impact a specific commercial entity or industry unit), political (making a statement, influencing the outcome of an election, forcing a particular political outcome) or various malicious incitements. Terrorist attacks against the food sources still remain an aggressive and effective weapon in the strategic planning of many state governments, particularly those with reduced conventional weaponry, and can have a huge economic and social impact (Rasco \& Bledsoe, 2005).
The World Health Organization (WHO) defines food terrorism as "an act or threat of deliberate contamination of food for human consumption with biological, chemical and physical agents or radionuclear materials for the purpose of causing injury or death to civilian populations and/or disrupting social, economic or political stability" (WHO, 2002). Terrorists can attack the food supply at several stages along the food chain by targeting:

- food production systems - crops and livestock during production, harvesting, storage and transport (agricultural bioterrorism or agroterrorism);

- processed foods during their processing, manufacturing, storage, transport, distribution and service (terrorism targeting processed foods).

The main tools for the purposes of food bioterrorism are the foodborne zoonotic pathogens such as viruses, bacteria or their toxins and parasites, which enter the body through the gastrointestinal tract by consuming infected food products or drinking contaminated water. One of the most used means for the purposes of agroterrorism are the agents that have impact both on animal and human health the zoonotic pathogens. These pathogens are known in the bioterrorism also as “double agents" (Friend, 2006).

\section{BRIEF HISTORY OF THE BIOTERRORISM}

Use of infectious agents as bioweapons against humans and animals is not a new concept. Historically, since ancient and medieval times, many efforts for spread of infectious diseases during wars have been made, using human and animal carcasses, drinking water pollution and other ways having devastating impact on the enemy. 
Many examples are documented - in 1155 Emperor Barbarossa poisoned water wells with human bodies in Tortona, Italy; in 1346 Tartar forces catapulted bodies of plague victims over the city walls of Kaffa (now Feodosia), Crimean Peninsula; in 1495 Spanish mixed wine with blood of leprosy patients to sell to their French foes in Naples, Italy (Riedel, 2004).

The spread of smallpox by the British forces through infected blankets and handkerchiefs given as gifts to the Native Americans (American Indians) in 1763, resulting in an epidemic with tens of thousands of victims, is the most cited example of biological warfare, although it is still arguable whether it was an intentional act of destroying native tribes or an incident. The rapid development of microbiology during the $19^{\text {th }}$ and the $20^{\text {th }}$ century made possible the isolation and production of stocks of specific pathogens. There is evidence that during the World War I, the Germans and French have attempted to distribute anthrax and glanders by infected cattle and horses sent to the United States and other countries, and by infected sheep exported to Russia (Riedel, 2004; Friend, 2006).

The enormous number of civilian and military victims resulting from the use of chemical weapons led to adoption of the Protocol for the Prohibition of the Use in War of Asphyxiating, Poisonous or Other Gases and of Bacteriological Methods of Warfare (Geneva Protocol) of 1925. However, this Protocol is addressed to a general prohibition of chemical and biological weapons and does not regulate their production, storage and transfer. In the period between the two world wars and during World War II many states developed research programs on bioweapons. The most terrifying of them was the Japanese programme, which took tens of thousands of victims. The Japanese tested at least 25 different pathogens on prisoners and unsuspecting civilians. During the war, the Japanese army poisoned more than 1000 water wells in Chinese villages to study cholera and typhus outbreaks. Japanese planes dropped plague-infected fleas over Chinese cities or distributed them by means of saboteurs in rice fields and along roads. Some of the epidemics they caused persisted for years and continued to kill more than 30,000 people in 1947 (Frischknecht, 2003). In 1942, Brucella suis was weaponised in the USA, placed into bombs and tested with animal targets in field trials between 1944 and 1945. Later in 1969, the USA declared that the offensive Brucella programme had been terminated and all biological weapon munitions were destroyed (Doganay \& Doganay, 2013).

International public concerns related to ongoing biological weapons research after World War II led to the development of stricter measures. The Biological Weapons Convention (BWC) of 1972 prohibits the development and production of microbial or other biological agents. Permission for possessing such agents for prophylactic, protective or other peaceful purposes seems to be used for exploring their applications as weapons, including non-lethal weapons degrading materials as fuels, lubricants, metal structures, etc. However, the ban on biological weapons is absolute, even if a weapon is created with the intention to be used in non-lethal manner (Tumbarska \& Petkov, 2017). There are examples demonstrating that some nations continued to carry out activities prohibited by the BWC. As a result of an accidental release of anthrax spores from a research facility in Sverdlovsk (now Ekaterinburg), Russia in 1979, at least 94 people who lived or worked 
within $4 \mathrm{~km}$ in a narrow zone became infected, of whom at least 68 died. The extensive cleanup, vaccinations, and medical interventions managed to save about 30 of the victims, but livestock deaths from anthrax extended out to $50 \mathrm{~km}$ (Meselson et $a l .$, 1994). The intentional use of anthrax as a biological weapon can has much more devastating effect on human and animal health. As a result of a bioterrorist attack with anthrax in Rhodesia (now Zimbabwe) during the War for independence in $1970 \mathrm{~s}$, about 10,000 of people seeking independence became sick, hundreds of whom died, and nowadays Zimbabwe is still endemic (Friend, 2006). Another example for deliberate use of anthrax, but without victims, was registered in Japan, when the religious group "Aum Shinrikyo" released B. anthracis in the period between 1990 and 1995 (Schmid \& Kaufmann, 2002).

In the last decades only a few attempts of using biological agents, with a limited scale of casualties are documented. Most emblematic among them is the distribution of anthrax-infected letters by postal services in the USA in October 2001 which caused 22 cases of anthrax (11 inhalational, 11 cutaneous), five of the inhalational cases with fatal outcome. However, the billions of anthrax spores contained in those letters could potentially induce a major epidemic, including many more deaths. Created fear in society disturbed people's life and public services, resulting in costly investigations. This accident demonstrated how the occurrence of a small number of infections can create fear and have an enormous psychological impact (Jernigan et al., 2002; Friend, 2006).

In response to the growing threats of bioterrorism, many developed countries and international organisations elaborated strategic plans and specific measures to reduce vulnerability to such attacks, which include a complex of activities concerning preparedness, planning, detection and surveillance, laboratory analysis, emergency response, communication systems, as well as training and research being integral components of these measures' implementation. The European Commission (EC) adopted a strategy to enhance intracommunity cooperation against the bioterrorist threats, which requests member states to create capabilities for rapid detection and identification of deliberate releases of biological agents.

\section{FOODBORNE ZOONOTIC AGENTS WITH FOOD BIOTERRORISM POTENTIAL}

Biological weapons are attractive to terrorists with the unique characteristics of biological agents: difficult detection; invisibility (because of delayed effect); relatively easy and inexpensive production; wide availability and easy dissemination among animal and human populations.

The main goals of the biological weapons are to cause morbidity, adverse health effects and death on a large scale within a very short time. Unlike the effects of conventional weapons, the effects of biological agents are not instantaneous and require few hours to weeks before the symptoms appear in the affected population (Thavaselvam \& Vijayaraghavan, 2010). Using an agent for biological attack requires obtaining of the agent, its multiplication in a way to retain its viability and pathogenicity, and developing a method ensuring its introduction into the human body in amounts sufficient to cause disease (Jansen et al., 2014).

The "ideal" bioweapon should have the following characteristics (Banjari, 2018):

- inexpensive and easy to produce; 
- highly lethal or infectious;

- resistant to environmental factors;

- no effective treatment available;

- low infectious dose;

- transmitted via air, water and food;

- transmitted person-to-person.

Fortunately, such a perfect weapon does not exist, but terrorists can successfully use less sophisticated weapons which can be easily produced. Some experts point out that terrorists, compared to the military, have even wider array of opportunities, from which to choose. For example, terrorists might not require long-term storage or mass delivery; they might need a less effective or lower-quality weapon, or a weapon that is effective over smaller distances, than would be required for battlefield use. Experts believe that aerosols are the most suitable method to be used in a potential bioterrorist attack, because they are the most effective means of widespread dissemination. However, the aerosolisation of the agent and its precise and extensive dispersing while preserving its virulence is a serious technical challenge (Ryan, 2008; Al-Agamy, 2011).

In 2000, the US Center for Disease Control and Prevention and the National Institute of Allergy and Infectious Disease (NIAID) categorised biological agents into three groups: $\mathrm{A}, \mathrm{B}$ and $\mathrm{C}$, based on the level of risk they represent for the US national security - potential for dissemination, expected rate of mortality, public panic and social disruption (Anonymous, 2000; Greenfield et al., 2002). The biological agents with potential for use as weapons are presented in Table 1.

\section{Bacillus anthracis}

Bacillus anthracis is the etiological agent of anthrax - an acute zoonotic disease of livestock and humans. B. anthracis is a
Gram-positive, rod-shaped, endosporeforming, facultative anaerobic bacterium. The spores of $B$. anthracis can persist in soil for decades and they are the usual infective form. This pathogen commonly affects domestic and wild animals and also causes a rare but lethal infection in humans. Anthrax can be spread to humans by several ways - by inhalation of spores, gastrointestinal (by food products), cutaneous (by injured skin) and in rare cases by direct contact (Greenfield et al., 2002; Schmid \& Kaufmann, 2002). The respiratory form of disease is highly lethal, therefore the inhalation of $B$. anthracis spores is the most frequently used for bioterrorism. The spores are highly resistant to sunlight, temperature and disinfectants, and can be easily dispersed over large population by missile, bombs and flying air crafts. In addition, the spores can maintain their virulence for decades and they can be milled to the ideal particle size for optimum infection of the human respiratory tract, which makes anthrax most selective as a biological weapon (Pal et al., 2017). Spread through intentionally contaminated with spores food products and animal feed such as wheat flour, grains and cereals is also possible (Wedman-St Louis, 2015).

\section{Clostridium botulinum}

Clostridium botulinum is a Gram-positive, spore-forming, anaerobic bacterium that causes botulism. It is common in soils, animal excrements, and gastrointestinal tract of birds and mammals (Ermenlieva et al., 2018). C. botulinum produces a toxin, which is considered one of the most poisonous substances in the world and 100,000 times more toxic than sarin (Broussard, 2001). A single gram of crystalline toxin could kill more than 
Foodborne zoonotic agents and their food bioterrorism potential: A review

Table 1. Categorisation of critical biological agents*

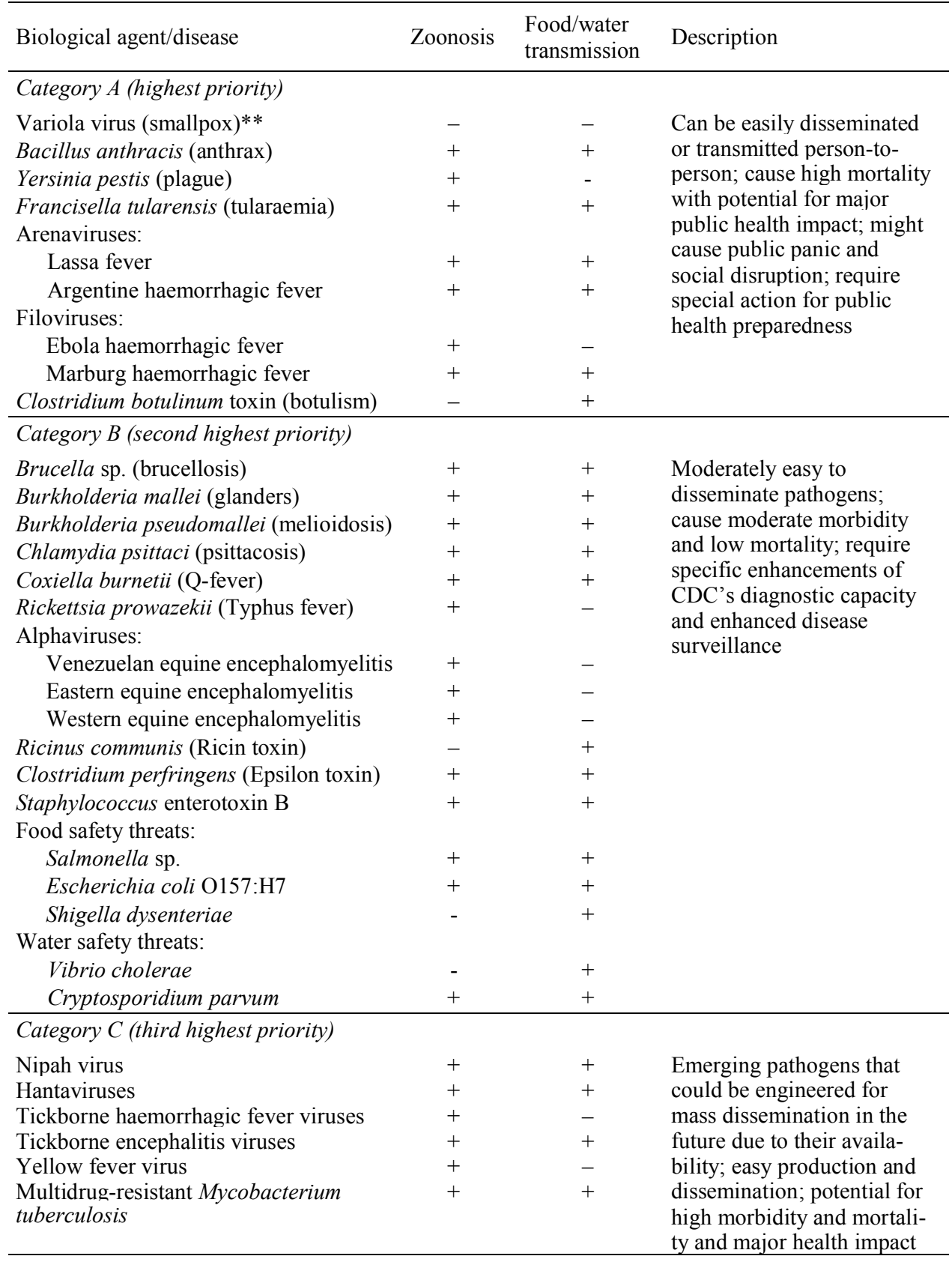

* according to Anonymous (2000): ** Variola maior (smallpox) is the only disease of Category A without animal source. This made development of effective vaccine possible and smallpox was eliminated through a worldwide vaccination campaign. Its eradication was officially declared by the WHO in 1979. 
$1,000,000$ people. Botulinum toxin is a muscle paralysing agent, whose action begins in the nervous system with the shutdown starting at the head and moving down through the body (Wedman-St Louis, 2015). Symptoms of botulism begin within 24 to $36 \mathrm{~h}$ after ingestion of food contaminated with botulinum toxin, and comprise abdominal cramps, headache, and vomiting. Late symptoms of the disease include paralysis of eye muscles, difficulty in swallowing, speech, and breathing (Ermenlieva et al., 2018). The neurotropic action and fast appearance of symptoms make botulinum toxin an effective bioterrorist agent especially in fast food restaurants (Wedman-St Louis, 2015).

\section{Clostridium perfringens}

Clostridium perfringens is a common anaerobic bacterium associated with three distinct disease syndromes: gas gangrene (clostridial myonecrosis), clostridial food poisoning and enteritis necroticans. Gas gangrene is a well-recognised life-threatening emergency due to the clostridial toxins responsible for the high mortality associated with myonecrosis, producing the characteristic intense pain that is out of proportion to the size of the wound. C. perfringens produces large amounts of carbon dioxide and hydrogen, which cause intense swelling and give rise to the term "gas" gangrene. Clinical symptoms also include necrosis, dark red serous fluid, and numerous gas-filled vesicles in affected tissues. Clostridial food poisoning is characterised by abdominal cramps, diarrhoea and dehydration, which begin eight hours to one day after consumption of contaminated food. The illness is selflimiting, usually within $24 \mathrm{~h}$, but less severe symptoms may persist for 1-2 weeks. The more serious, but rare enteritis ne- croticans is caused by ingesting food contaminated with type $\mathrm{C}$ strains. It begins as a result of ingesting large numbers of $C$. perfringens but progresses to intestinal necrosis and septicaemia (Clarke, 2005; Ermenlieva et al., 2018).

Brucella spp.

Brucella spp. are Gram-negative bacteria that unifies six species $-B$. melitenis, $B$. abortus, B. suis, B. canis, B. ovis and B. neotomae (Al-Mariri, 2015). The brucellae cause abortions and infertility in their natural hosts (goats, cattle, sheep, pigs and dogs). The economic impact of brucellosis can be significant to both the owners of the livestock and to the countries where they are located due to the imposition of trade barriers. Humans contract brucellosis by direct contact with infected animals or their products and clinical symptoms can vary from asymptomatic subclinical infection (malaise, sweating, arthralgia and fever) to lethal endocarditis. The biological and pathogenic properties of Brucella spp. (high infectivity via aerosol route; causing debilitating disease; prolonged antibiotic treatment and absence of effective vaccines for humans) make them suitable as biological warfare agents (Valderas \& Roop, 2006).

\section{Francisella tularensis}

Francisella tularensis is a Gram-negative, rod-shaped, aerobic bacterium and the causative agent of tularaemia. Tularaemia is a zoonosis, which can be spread to humans by insect bite, ingestion of contaminated food or water and by inhalation. Six clinical forms are recognised according to the bacteria's portal of entry: ulceroglandular and glandular forms (regional lymphadenopathy with or without a cutaneous eschar); oculoglandular form (conjunctivi- 
tis with regional lymphadenopathy); oropharyngeal form (pharyngitis with cervical lymphadenopathy); pneumonic form (following inhalation of a contaminated aerosol or through haematogenous spread of bacteria to the lungs) and typhoidal form (a severe systemic febrile illness without a detectable primary infection site). The most frequent disease presentation - the typhoidal or septicaemic form, develops after a 2-10 days incubation period with fever, prostration, cough and weight loss. Without treatment, the mortality rate can reach 35\% (Bellamy \& Freedman, 2001; Maurin, 2015).

\section{Staphylococcus aureus}

Staphylococcus aureus is a Gram-positive bacterium that produces enterotoxins. Not all of them are lethal, but they may result in significant morbidity. The staphylococcal enterotoxin B (SEB) is the most common cause of classic food poisoning and has been studied as a potential agent of bioterrorism, as it is very stable in the environment, easily soluble in water and aerosolised, and can cause widespread systemic damage and multiorgan system failure. The incubation period is between 1 and 8 hours. Classic symptoms are fever, headache, nausea, vomiting, cramping abdominal pain and diarrhoea, which incapacitate the patient. Most cases are selflimiting and resolve in 8-24 hours. In very high dosages, SEB may lead to septic shock and death (Clarke, 2005).

\section{Enteropathogens}

Toxigenic Escherichia coli, Salmonella sp. and Vibrio cholerae are potential biological threats. They have to be introduced into food or water supplies in large amounts to be recognised as biological weapons. The clinical symptoms of diseases they cause are expressed in febrile diarrhoeal illnesses, which are rarely fatal. The use of enteropathogens for bioterrorist purposes would create anxiety, but would be minimally disruptive to society, because they are easily treatable with antimicrobial agents (Cunha, 2002). Shigella sp. is one of the most formidable foodborne and waterborne pathogens, which can induce bloody diarrhoea with very low inocula and can be transmitted from person-to-person contact through the faecal-oral route and it is related to late development of haemolytic uraemic syndrome (Al-Agamy, 2011).

Despite the many published data in the scientific literature for use of pathogenic agents in the bioterrorism, a small number of cases of intentional livestock and food contamination are confirmed and officially documented (Table 2 ).

\section{RISK ASSESSMENT AND FOOD CONTROL}

The development of science and technologies increased the knowledge of interactions between the pathogens and their hosts, which led to development of countermeasures as well as different methods for rapid pathogen detection and identification. However, the advance of biotechnologies, which offers a great promise for improving and protecting human and animal health, can also make it easier for terrorists to create and deploy effective biological weapons (Franz, 2002). In addition, the globalisation, urbanisation and changes in consumer's habits increase the number of people buying and eating food prepared in public places. The extension of the food production and supply as well as the international trade with foods, makes the food-supply chain susceptible to different threats (Krivohlavek, 2018). In this respect, the food control and risk 
Table 2. Reported cases of food bioterrorism

\begin{tabular}{llll}
\hline Biological agent & $\begin{array}{l}\text { Contaminated } \\
\text { livestock/foods }\end{array}$ & Country/year & Reference \\
\hline $\begin{array}{l}\text { Brucella suis } \\
\text { Bacillus anthracis }\end{array}$ & $\begin{array}{l}\text { Pigs } \\
\text { Cattle }\end{array}$ & $\begin{array}{l}\text { USA, 1944-1945 } \\
\text { Rhodesia } \\
\text { (Zimbabwe), 1970s }\end{array}$ & $\begin{array}{l}\text { Doganay \& Doganay, 2013 } \\
\text { Friend, 2006 }\end{array}$ \\
Salmonella typhimurium & Salad bars & USA, 1984 & $\begin{array}{l}\text { Török } \text { et al., 1997 } \\
\text { Greenfield } \text { et al., 2002 }\end{array}$ \\
Salmonella typhimurium & Milk & USA, 1985 & Elad, 2005 \\
Hepatitis A virus & Clams & China, 1991 & Elad, 2005 \\
Salmonella enteritidis & Ice cream & USA, 1994 & Kolavic et al., 1997 \\
Shigella dysenteriae & $\begin{array}{l}\text { Muffins and } \\
\text { doughnuts }\end{array}$ & USA, 1996 & Greenfield et al., 2002 \\
Escherichia coli & Radish sprouts & Japan, 1996 & WHO, 2002 \\
O157:H7 & & & \\
\hline
\end{tabular}

assessment along the food-supply chain are of great importance for the prevention of potential terrorist acts.

As a result of the terrorist attacks in 2001 and the increasing emphasis on national security, food security became a major priority for the food industry in the USA and other developed countries, where the food safety is closely controlled both by the government and the private sector. Food safety infrastructures offer different means for preventing and mitigating sabotage along the food supply chain. In addition, international food safety initiatives and enhanced disease surveillance, and response activities can be developed for preventing and responding quickly to food bioterrorism. On the other hand, foods are among the most vulnerable to contamination by biological agents, but deliberate contamination of food might, in some regards, be easier to control than attacks through air or water (WHO, 2002).

All units along the food chain - from farm to table, involve an element of risk and it is critical to ensure effective risk management of food safety. Risk can be defined as "a function of the probability of an adverse health effect and the severity of that effect, consequential to a hazard(s) in food". Risk analysis includes three main components: risk assessment, risk management and risk communication (Uhlenhopp, 2002). Risk assessment (or quantification of risk) is the science that considers hazards (biological, chemical, physical and radiological), the probability of their occurrence and the potential effects if they do occur. Risk management is the mechanism of analysing policy alternatives following risk assessment, identifying and implementing appropriate controls including regulation (prevention, detection and control of food sabotage). Risk communication is defined as "the interactive exchange of information and opinions concerning risk among risk assessors, risk managers, consumers and other interested parties" (Manning et al., 2005).

According to Elad (2005) risk assessment of food chain contamination (deliberate or not) includes the quantification of risk at the following important stages: 


\section{Microbial risk assessment}

This stage includes the specific properties of the pathogenic microorganism (zoonotic or not); its accessibility for the terrorists; the ways of its weaponisation (culturing to reach the doses necessary for realisation of the terrorist attack and additional procedures that may be required in the preparation of the final product for terrorist purposes); the delivery of the pathogenic microorganism at an effective dose (depending on its virulence, contagiousness, ability to multiply and spread in the environment after dissemination).

\section{Product-associated risk assessment}

This stage unifies the following points: geopolitical factors (the similarity/identity between the habits and foods consumed by the target populations and terrorist group, leads to decrease of risk, respectively the probability of intentional contamination); specific consumer populations (cases in which food products are to be consumed by specific groups of people, such as children, whose susceptibility to infections is higher, or some ethnic groups who consume particular food products); psychological impact (contamination of certain foods, such as those used in religious rituals, may render a stronger psychological effect than contamination of ordinary foods).

\section{Processing chain-related risk assessment}

Food processing is the key point or "bottle-neck" in the deliberate contamination of foods. Food products can be contaminated directly or indirectly by infecting the animals through their feed or environment. In the first case, the pathogenic microorganisms must be sufficiently resistant to the environmental conditions and to survive the food processing. In the second case (if animals are targeted as bioweapon carriers), the pathogen should cause invisible clinical symptoms or such that disappear quickly, so as not to be noticed by the potential consumers.

Operational risk management as reported by the United States Department of Agriculture (Anonymous, 2001) includes the following six steps: a) identification of the hazards for each activity or step in the process of food preparation; b) assessment of the risks of each hazard (probability, severity and exposure); c) analysis of risk control measures for the potential hazards (investigation of specific strategies and tools that mitigate, reduce or eliminate risk); d) making control decisions (involving personnel impacted by the risk control in the selection of decision, evaluation of the impact on the operation of the risk control action, evaluation of all the positive and negative factors associated with the risk decision); e) implementation of risk controls (making clear implementation, establishment of accountability and promoting support); f) supervising and review (determination of the effectiveness of risk controls implemented for food or water safety and security).

The application of hazard analysis and critical control point (HACCP) systems in the food industry is an effective approach to establishing good production, sanitation and manufacturing practices that allow producing safe foods. HACCP systems provide control of the process through identifying points in the production process that are most critical to monitor and control. The main advantage of HACCP systems is that can be applied to control any stage in the food production, and are designed to provide enough feedback to direct corrective activities, so the inspectors should be able to detect contamination during food processing (Unnevehr \& Jensen, 1999; Sekheta et al., 2006). 
HACCP systems are directed to prevent unintentional food contamination resulting from human error or ignorance. However, to prevent deliberate contamination along the food supply chain, the control measures should be emphasised.

\section{CONCLUSION}

The use of biological agents as weapons for the purposes of food bioterrorism can have fast and devastating effect on human and animal health. Even a small scale biological attack might result in enormous economic and social consequences. At present, the potential of zoonoses as biological weapons for mass biological attacks is limited due to technical difficulties in their weaponisation. However, the rapid technological advances may soon provide the terrorists with opportunities of modifying some zoonotic agents and creating means for their dissemination within large groups of population. Despite the development of different countermeasures, methods for rapid pathogen detection and identification, and the application of HACCP systems in the food industry, the threat of terrorist acts should not be underestimated and any efforts should be made for strengthening food control measures to prevent bioterrorist acts.

\section{REFERENCES}

Al-Agamy, M. H. M., 2011. Tools of biological warfare. Research Journal of Microbiology, 6, 193-245.

Al-Mariri, A., 2015. Isolation of Brucella melitensis strains from Syrian bovine milk samples. Bulgarian Journal of Veterinary Medicine, 18, 40-48.

Anonymous, 1972. United Nations Office for Disarmament Affairs (UNODA). Biological Weapons. https://www.un.org/disarma- ment/wmd/bio (31 March 2019 date last accessed).

Anonymous, 2000. Center for Disease Control and Prevention. Biological and Chemical Terrorism: Strategic Plan for Preparedness and Response. Recommendations of the CDC Strategic Planning Workgroup. Morbidity and Mortality Weekly Report (MMWR), 49, 1-26.

Anonymous, 2001. United States Department of Agriculture. Food safety and security: operational risk management systems approach. Department of Health and Human Services, US Food and Drug Administration, Center for Food Safety and Applied Nutrition, College Park, MD, pp. 1-25. https://seafood.oregonstate.edu/sites/agsci d7/files/snic/food-safety-and-security-ormsystems-approach2001-fda.pdf (31 March 2019 date last accessed).

Banjari, I., 2018. Food and Bioterrorism - The case of airline catering. In: NATO Science for Peace and Security Series A: Chemistry and Biology, pp. 229-237.

Bellamy, R. J. \& A. R. Freedman, 2001. Bioterrorism. QJM: An International Journal of Medicine, 94, 227-234.

Broussard, L., 2001. Biological agents: Weapons of warfare and bioterrorism. Molecular Diagnosis, 6, 323-333.

Clarke, S. C., 2005. Bacteria as potential tools in bioterrorism, with an emphasis on bacterial toxins. British Journal of Biomedical Science, 62, 40-46.

Cunha, B. A., 2002. Anthrax, tularemia, plague, ebola or smallpox as agents of bioterrorism: recognition in the emergency room. Clinical Microbiology and Infection, 8, 489-503.

Doganay, G. D. \& M. Doganay, 2013. Brucella as a potential agent of bioterrorism. Recent Patents on Anti-Infective Drug Discovery, 8, 27-33.

Elad, D., 2005. Risk assessment of malicious biocontamination of food. Journal of Food Protection, 68, 1302-1305.

Ermenlieva, N., G. Tsankova, D. Naydenova, T. T. Todorova, D. Tsankova \& E. Geor- 
gieva, 2018. Foodborne Bacteria: Potential Bioterrorism Agents. In: Food Safety Some Global Trends, IntechOpen, pp. 5165.

Franz, D. R., 2002. The potential "bioweaponization" of zoonotic diseases. In: The Emergence of Zoonotic Diseases: Understanding the Impact on Animal and Human Health. Workshop Summary, Washington (DC): National Academies Press (US), pp. 10-25.

Friend, M., 2006. Biowarfare, bioterrorism, and animal diseases as bioweapons. In: Disease Emergence and Resurgence: The Wildlife-Human Connection, U.S. Department of the Interior, U.S. Geological Survey, Reston, Virginia, pp. 231-271.

Frischknecht, F., 2003. The history of biological warfare. European Molecular Biology Organization Reports, 4, 47-52.

Greenfield, R. A., D. A. Drevets, L. J. Machado, G. W. Voskuhl, P. Cornea \& M. S. Bronze, 2002. Bacterial pathogens as biological weapons and agents of bioterrorism. The American Journal of the Medical Sciences, 323, 299-315.

Jansen, H. J., F. J. Breeveld, C. Stijnis \& M. P. Grobusch, 2014. Biological warfare, bioterrorism, and biocrime. Clinical $\mathrm{Mi}$ crobiology and Infection, 20, 488-496.

Jernigan, D. B., P. L. Raghunathan, B. P. Bell, R. Brechner, E. A. Bresnitz, J. C. Butler, M. Cetron, M. Cohen, T. Doyle, M. Fischer, C. Greene, K. S. Griffith, J. Guarner, J. L. Hadler, J. A. Hayslett, R. Meyer, L. R. Petersen, M. Phillips, R. Pinner, T. Popovic, C. P. Quinn, J. Reefhuis, D. Reissman, N. Rosenstein, A Schuchat, W.-J. Shieh, L. Siegal, D. L. Swerdlow, F. C. Tenover, M. Traeger, J. W. Ward, I. Weisfuse, S. Wiersma, K. Yeskey, S. Zaki, D. A. Ashford, B. A. Perkins, S. Ostroff, J. Hughes, D. Fleming, J. P. Koplan, J. L. Gerberding \& the National Anthrax Epidemiologic Investigation Team, 2002. Investigation of bioterrorism-related anthrax, United States, 2001: Epidemiologic findings. Emerging Infectious Diseases, 8, 1019-1028.
Kolavic, S. A., A. Kimura, S. L. Simons, L. Slutsker, S. Barth \& C. E. Haley, 1997. An outbreak of Shigella dysenteriae type 2 among laboratory workers due to intentional food contamination. Journal of the American Medical Association, 278, 396398.

Krivohlavek, A., 2018. Food Safety, standards and norms against bioterrorism: Food safety and hazards. In: NATO Science for Peace and Security Series A: Chemistry and Biology, pp. 239-248.

Manning, L., R. N. Baines \& S. A. Chadd, 2005. Deliberate contamination of the food supply chain. British Food Journal, 107, 225-245.

Maurin, M., 2015. Francisella tularensis as a potential agent of bioterrorism? Expert Review of Anti-Infective Therapy, 13, 141144.

Meselson, M., J. Guillemin, M. Hugh-Jones, A. Langmuir, I. Popova, A. Shelokov \& O. Yampolskaya, 1994. The Sverdlovsk Anthrax Outbreak of 1979. Science, 266, 1202-1208.

Pal, M., M. Tsegaye, F. Girzaw, H. Bedada, V. Godishala \& V. Kandi, 2017. An Overview on Biological Weapons and Bioterrorism. American Journal of Biomedical Research, 5, 24-34.

Rasco, B. A. \& G. E. Bledsoe, 2005. Foods and the Bioterrorist Threat. In: Bioterrorism and Food Safety, CRC Press, Boca Raton London New York Washington, D.C., pp. 1-33.

Riedel, S., 2004. Biological warfare and bioterrorism: A historical review. Proceedings (Baylor University Medical Center, 17, 400-406.

Ryan, C. P., 2008. Zoonoses likely to be used in bioterrorism. Public Health Reports, 123, 276-281.

Schmid, G. \& A. Kaufmann, 2002. Anthrax in Europe: Its epidemiology, clinical characteristics, and role in bioterrorism. Clinical Microbiology and Infection, 8, 479-488. 
Sekheta, M. A. F., A. H. Sahtout, F. N. Sekheta, N. Pantovic \& A. T. Al Omari, 2006. Terrorist threats to food \& water supplies and the role of HACCP implementation as one of the major effective and preventive measures. Internet Journal of Food Safety, 8, 30-34

Solodoukhina, D., 2011. Food safety and bioterrorism from public health perspective. In: NATO Science for Peace and Security Series A: Chemistry and Biology, pp. 17-25.

Thavaselvam, D. \& R. Vijayaraghavan, 2010. Biological warfare agents. Journal of Pharmacy \& BioAllied Sciences, 2, 179188.

Török, T., R. V. Tauxe, R. P. Wise, J. R. Livengood, R. Sokolow, S. Mauvais, K. A. Birkness, M. R. Skeels, J. M. Horan \& L. R. Foster, 1997. A large community outbreak of Salmonella caused by intentional contamination of restaurant salad bars. Journal of the American Medical Association, 278, 389-395.

Tumbarska, A. \& P. Petkov, 2017. Non-lethal weapons in the context of the restrictions required by international law. In: Proceedings of Scientific Conference "Actual Problems of Security”, National Military University "V. Levski", Veliko Tarnovo, pp. 148-158 (BG).

Tumbarska, A., 2018. The non-lethal technologies against the terrorism. European Journal of Engineering Research and Science, 3, 41-46.

Uhlenhopp, E. K., 2002. Livestock bioterrorism and the need for veterinary services in a global society: Risk analysis, hazard analysis and critical control points (HACCP). Journal of Veterinary Medical Education, 29, 212-215.
Unnevehr, L. J. \& H. H. Jensen, 1999. The economic implications of using HACCP as a food safety regulatory standard. Food Policy, 24, 625-635.

Valderas, M. W. \& R. M. Roop, 2006. Brucella and bioterrorism. In: Microorganisms and Bioterrorism. Infectious Agents and Pathogenesis, eds B. Anderson, $\mathrm{H}$ Friedman \& M. Bendinelli, Springer, Boston, MA, pp. 139-153.

Wedman-St Louis, B., 2015. Food bioterrorism. Journal of Bioterrorism \& Biodefense, 6, 133.

World Health Organization, 2002. Terrorist threats to food: Guidance for establishing and strengthening prevention and response systems (Food Safety Issues), https:// apps.who.int/iris/bitstream/handle/10665/4 2619/9241545844.pdf? sequence $=1$ \&isAll owed=y (31 March 2019 date last accessed).

Paper received 06.11.2018; accepted for publication 22.02.2019

\section{Correspondence:}

Assist. Prof. Yulian Dimitrov Tumbarski, DVM, PhD

Department of Microbiology

University of Food Technologies

26, Maritza Blvd., Plovdiv, 4002, Bulgaria e-mail: tumbarski@abv.bg 